\title{
Policía y Administración de Justicia (*)
}

\author{
JAVIER BOIX REIG \\ Catedrático de Derecho Penal
}

\begin{abstract}
A quienes han sido mis alumnos en la Universidad de Alicante
\end{abstract}

Quiero, en primer término, agradecer a los organizadores de este Seminario la invitación que me formularon para participar en el mismo, en el marco de las actividades que viene desarrollando la Universidad Internacional Menéndez y Pelayo.

La necesidad de una policía debidamente especializada, que cumplimente sus funciones en el orden judicial, con la necesaria independencia respecto al ejecutivo que ello requiere, justifica sobradamente este Seminario, tendente a analizar, por lo que a la Policía Judicial se refiere la confusa normativa existente al respecto, lógica consecuencia de haber estructurado un modelo de Policía Judicial poco comprometido.

\section{Análisis de regulación sobre Policía Judicial}

No es el momento de reiterarles y explicarles la normativa que se encuentra vigente sobre la Policía Judicial. Sin duda que ya habrá sido analizada en este Seminario. Sólo recordarles o enunciarles la misma a efectos de situar lo que considero ideas básicas de dicha regulación.

(*) Intervención en la Mesa Redonda que tuvo lugar el día 18 de julio de 1989 en el Seminario «Policía y Sociedad», organizado por la Universidad Internacional Menéndez y Pelayo y la Dirección General de Policía, y celebrado en el Palacio de La Magdalena de Santander. 
En el orden constitucional debe significarse que junto con el artículo 104 de la Constitución, en el que se establece la dependencia de las Fuerzas y Cuerpos de Seguridad del Gobierno y delimita su misión en cuanto a la protección del libre ejercicio de los derechos y libertades y a garantizar la seguridad ciudadana, el artículo 126 especifica que:

«La policía judicial depende de los Jueces, de los Tribunales y del Ministerio Fiscal en sus funciones de averiguación del delito y descubrimiento y aseguramiento del delincuente, en los términos que la Ley establezca.»

El mencionado precepto constitucional supone, sin duda, un importante avance desde la perspectiva de consolidación del Estado de Derecho. No obstante, el avance puede ser más formal que real. Estamos ante un precepto aceptable en la forma, inexpresivo en el fondo e insuficiente por razones históricas y políticas. Valoración general en la que coincido y me remito a Ruiz Vadillo.

En el ámbito de la legislación ordinaria recordar la antigua, pero vigente regulación, del artículo 282 y siguientes de la Ley de Enjuiciamiento Criminal (Lecrim), los artículos 443 a 446 de la Ley Orgánica del Poder Judicial (LOPJ), los artículos 29 a 38 de la Ley Orgánica de Fuerzas y Cuerpos de Seguridad del Estado (LOFCSE), y el Real Decreto 769/1987, de 19 de junio, de la Policía Judicial (DPJ).

1.-De este conjunto normativo cabe desprender que la Policía es Policía Judicial en todo caso, en tanto actúe como tal. No obstante, varían sus cauces de intervención de acuerdo con un sistema de organización de la Policía Judicial, al que claramente se refiere Moreno Catena, distinguiendo en Fuerzas y Cuerpos de Seguridad, en general, como Policía Judicial, las Unidades Orgánicas de Policía Judicial y, en tercer lugar, las llamadas Unidades adscritas de Policía Judicial que como parte de las anteriores se adscriben materialmente a los órganos judiciales. Puede decirse que estas últimas unidades son las que requieren una mayor especialización, las que en realidad gozan de esa estrecha relación con los órganos judiciales y fiscales, por más que los niveles de especialización sean exigibles al conjunto de las unidades orgánicas. 
Debe significarse que las referidas Unidades Orgánicas, y en consecuencia las adscritas al ser parte de ellas, vienen integradas por Guardia Civil y Cuerpo Nacional de Policía, sin que en sentido estricto sean Policía Judicial las policías autonómicas y las locales, por más que puedan cumplimentar las funciones genéricas de policía judicial y labores de auxilio a las unidades de Policía Judicial, bien por requerirlo el órgano judicial o fiscal o por solicitar en colaboración miembros genuinos de las Unidades de Policía Judicial (ver art. 29.1. LOFCSE). En la práctica es fácil obviar las dificultades formales que existen para la colaboración de las policías autonómicas y locales. No obstante, sería deseable que las diferentes clases de policías pudieran integrar las unidades orgánicas y adscritas de policía judicial, para lo que sería necesario modificar la regulación al respecto.

2.-Las competencias atribuidas a la Policía Judicial derivan con carácter genérico, del artículo 126 de la Constitución: averiguación del delito y descubrimiento y aseguramiento del delincuente. Funciones que se reproducen expresamente en el artículo 443 de la LOPJ, si bien se especifican las propias de las unidades de Policía Judicial en el artículo 445 de esta última ley.

Por más que estemos ante funciones específicas, atribuidas a la llamada Policía Judicial o mejor a sus unidades, es lo cierto que ello no excluye la posibilidad de acudir con carácter general a los diversos cuerpos de Policía y para muy variados temas, referidos al ámbito penal o no.

Partiendo de que la realidad nos indica que la actuación de las Fuerzas y Cuerpos de Seguridad tiene relación con la actividad judicial en un porcentaje más elevado, es lo cierto que puede suscitarse una cierta insuficiencia de competencias, si las contamos en los términos antes dichos. En este sentido se ha puesto de manifiesto la infrautilización cualitativa y cuantitativa de la Policía Judicial, por parte de los propios titulares de los órganos judiciales. Así debe destacarse la posible intervención de esta clase de Policía en cuestiones de orden civil (así, Ruiz Vadillo) e incluso en el ámbito penal en su dimensión preventiva.

Estas últimas funciones o misiones preventivas, a las que incluso se refiere el artículo 33 LOFCSE, no empañarían la nota de exclusividad 
en sus funciones, que como característica específica requiere Segovia al configurar el concepto de Policía Judicial, ni menos aún se impide por los angostos términos en que configura el artículo 19 del Decreto 769/87 las funciones antedichas, dada la remisión específica que efectúa el citado artículo de la LOFCSE y al artículo 445 de la LOPJ, de tenor este último ciertamente amplio.

3.-Ciertamente que la nueva regulación de la Policía Judicial supone un avance desde la perspectiva de la independencia judicial; en ese sentido debo valorarla positivamente. De una concepción de dicha policía, a la que se atiene esencialmente la Ley de Enjuiciamiento Criminal, cifrada en la idea de auxilio a la función judicial se pasa a la dependencia funcional. Esto es importante, ya que permite profundizar en el concepto de independencia judicial y supone en definitiva un aseguramiento de la misma (de Esteban y López Guerra).

Pero, además, este proceso que podría calificarse de judicialización de la policía, permite no sólo garantizar en mayor medida la predicha independencia, sino también otorgar una mayor eficacia a la investigación policial, en el orden criminal, sobre si nos atenemos a la proyección jurídica que luego debe tener tal actuación.

Desde la perspectiva de la independencia judicial debe recordarse que la dependencia funcional de la Policía va a permitir con mucha mayor fluidez y garantía que sea el propio juez quien determine los criterios de inicio de la investigación criminal, seleccione los temas con evidente incidencia jurídico-penal y también indique cómo se realiza la investigación, preservando derechos fundamentales y planteando en términos jurídicos pruebas, de modo que luego sean viables también jurídicamente en el proceso, y finalmente valore los resultados de dicha investigación; valoración que no podrá estar teñida por criterios de oportunidad, sino por imperio del principio de legalidad. Se conjuga, en suma, mayor eficacia de la investigación con profundización de la independencia judicial.

Garantía de tal independencia es que la adscripción de policías a las unidades de policía judicial en sentido estricto, lo sea con carácter permanente. Nota esencial a la que alude Segovia al conceptuar esta clase de policía. 
Esa nota de permanencia supone la garantía de no remoción de los miembros adscritos a la unidad de policía judicial. Garantía que se contiene en los artículos 446 de la LOPJ, 34.1 de la LOFCSE y 16 del DPJ. En igual medida, habrá que incluir en el ámbito judicial la posibilidad de instar el ejercicio de la actividad disciplinaria.

Consecuencia de dicha característica será que los miembros de la Policía Judicial actuarán siempre según instrucciones del órgano judicial, o del fiscal en su caso, no pudiendo recibir instrucciones contrarias, o mejor cumplirlas, de superiores orgánicos, siquiera sean de orden técnicos. Están a las órdenes del Juez o Fiscal, y sólo se atienen a las instrucciones de éstos. En este sentido, es significativo el artículo 11 del DPJ.

Profundamente vinculado con la garantía de la no remoción, está el de la potestad para cesar, ya que aquella garantía quedaría sin contenido si dicha potestad se hiciera residir, sin más, en el ámbito del ejecutivo. El art. 24 del DPJ establece también la garantía de permanencia, y establece un cierto control de la misma por parte de la Comisión Provincial de Coordinación, la que en todo caso deberá emitir previo informe favorable, "con carácter preceptivo y vinculante», cuando un miembro de la Unidad vaya a dejar de pertenecer a la misma. Ha igual conclusión debe llegarse cuando se trata de ceses por causa legal o traslado. Cierto es que a su través no pueden entenderse más que justas causas para dejar de pertenecer a tales unidades. En todo caso, en garantía de que ello sea así y en orden a no perturbar el buen fin de posibles investigaciones en curso, no estaría de más una interpretación del artículo 24 del DPJ que diera juego a la Comisión Provincial de Coordinación en orden a controlar tales situaciones igualmente, debiera darse un papel más relevante al Juez o Fiscal que en ese momento esté dirigiendo la investigación, cuando cese el funcionario policial; cese que puede suponer graves perjuicios para la investigación en algunos casos. En ese sentido, debiera modificarse el artículo 16 del DPJ. Piénsese que, de contrario, puede vulnerarse el fundamento mismo, antes referido, de la no remoción y la finalidad del art. 446 de la LOPJ y del art. 34.1 de la LOFCSE, «en la remoción y separación, la excepción se puede convertir en regla general, ya que orgánicamente dicha Policía depende del Ministerio del Interior». 
4.-En todo caso, la doble dependencia de la Policía Judicial, que en realidad más se parece a auténticas situaciones de doble personalidad que en la práctica, en casos límites, pueden producir auténticos planteamientos que alegóricamente calificamos de esquizoides, nunca debe interpretarse o llevar a consecuencias restrictivas de la independencia jurisdiccional.

Por más que puedan existir poderosas razones para mantener la dependencia orgánica del Ministerio del Interior (a las que alude Moreno Catena), es lo cierto que el artículo 126 de la Constitución alude a una dependencia esencial de la Policía Judicial que en ningún caso debe limitarse por dependencias orgánicas de la clase que fueren, a las que por cierto no alude dicho precepto constitucional. En ese sentido, prima en todo caso, sobre cualquier otra consideración, la llamada dependencia funcional, y si existen problemas derivados de la dependencia orgánica que directa o indirectamente afecten a la funcional, deben solventarse siempre en favor de la función constitucional expresamente referida en el artículo 126 citado. Y en caso de colisión entre preceptos ordinarios, hay que atenerse siempre a criterios de interpretación que potencien la independencia judicial y que sea conforme a la Constitución.

\section{Referencia a cuestiones en particular}

La dependencia funcional a que se encuentra sometida la Policía Judicial, la interpretación conforme a la Constitución que impera ante cualquier conflicto que surja con motivo de situaciones derivadas de su dependencia orgánica, debe redundar, como ya se ha dicho, no sólo en una profundización de la independencia judicial sino también en una mayor virtualidad y eficacia de la investigación criminal, que siempre deberá producirse conforme a los derechos fundamentales.

Voy a plantear alguna cuestión concreta, susceptible de ser debatida en ulterior coloquio, que considero pueden adquirir relieve en el marco de este Seminario.

1.-Por lo que se refiere a los atestados que practique la Policía Judicial, hay que afirmar que su consideración jurídica como denuncia sigue siendo inamovible (así, Queralt y Jiménez). 
No obstante, debe destacarse la importancia de la estructuración de las Unidades adscritas, desde la consideración de su necesaria especialización y formación técnica y habida cuenta que actuarán bajo la dirección jurídica que su actuación tendrá por parte del Juez o Fiscal. Ello deberá repercutir en una mayor eficacia de la investigación en curso y en un incremento de seguridad jurídica de la policía actuante y de virtualidad jurídica de su actuación en el posterior procedimiento. Al menos, así debería de ser.

En este ámbito, debe subrayarse el papel de la figura del Comisionado. Tal calificación no atribuye mayores consecuencias jurídicas a su actuación. La «especial consideración»a que se refiere el art. 14 del DPY (ver también el art. 11), es sólo estrictamente técnica, en el marco del "valor reconocido en las leyes», que no es otro, como ya se ha dicho, que el de denuncia.

Como igualmente se ha señalado, su actuación habrá de significarse en orden al fotalecimiento de la investigación, a no perjudicar su continuidad y la averiguación de delito realizado y de cara a posibilitar en mayor medida la reproducción probatoria en el procedimiento penal y, en última instancia, en el Juicio Oral.

Piénsese que incluso las diligencias de investigación que promueva el Ministerio Fiscal, a cuyas órdenes está la Policía Judicial, tampoco tienen mayor valor jurídico que el ya aludido. Lógico es que circunscribamos, en consecuencia, las actuaciones de la Policía Judicial en los términos dichos. La presunciación de autenticidad que las investigaciones del Fiscal tienen, según el artículo 5 de su Estatuto, no se refiere más que al hecho de la incoación de dichas diligencias y que las actuaciones que se dice haber llevado a cabo efectivamente lo han sido (así, Varela Castro). Pero no ofrecen prueba respecto la realidad material a que se refieren dichas actuaciones. En la misma línea debe interpretarse el artículo 785 bis de la Ley de Enjuiciamiento Criminal, incorporado en la reforma de 1988, que en el fondo nada nuevo ofrece en esta materia, respecto a las funciones y validez jurídica de sus actuaciones, en relación con las que ya le atribuía el Estatuto del Ministerio Fiscal de 1981. La reforma citada no ha tribuido, como algún sector doctrinal pretendía, auténticas funciones instructoras al Fiscal. 
Desde la perspectiva de la eficacia y virtualidad jurídica de su actuación, la dirección técnica antes aludida ofrece mayores posibilidades reales de que los reconocimientos se practiquen con las necesarias garantías jurídicas (art. 369 Lecrim.), evitando invalidaciones posteriores por defectos en su práctica, o de que las actuaciones en entradas y registros tengan también lugar con las imprescindibles garantías jurídicas (art. 545 y sgs. Lecrim.); haciendo constar en las circunstancias del art. 551 de la Lecrim. el consentimiento expreso, con la autorización judicial a que se refiere el art. 558 de la Lecrim, y llevando a cabo su práctica con presencia del Secretario y dos testigos y presencia del Juez o delegado (art. 572 Lecrim.), pudiendo plantear respecto este último la intervención del Comisionado.

Consecuencia de lo anterior es la adopción de las garantías que establece la Lecrim. en orden a la preservación del objeto del delito, dado que supone una actuación que preconstituye prueba. Dada esta proyección jurídica en el procedimiento penal ulterior habrá que requerir la presencia judicial (art. 574 Lecrim.) en tal caso. Así, se ha afirmado que «debido a la circunstancia de que la finalidad del registro es recoger los efectos e instrumentos del delito, o lo que es lo mismo, preconstituir la prueba, disponiendo su custodia hasta el momento del Juicio Oral, dicho acto ha de revestir las notas esenciales de la prueba: la intervención de la Autoridad Judicial, de un lado, y la posibilidad de contradictorio de otro» (Gimeno). En esta línea, dicho autor reputa desafortunado el art. 28 , pf. $2 .^{\circ}$, e), que atribuye entre otras funciones a las Unidades Adscritas la práctica de la «recogida de pruebas», ya que la policía, sea o no judicial, no puede por sí misma recoger prueba alguna, pues la prueba requiere la intervención de una Autoridad institucional dotada de independencia judicial. Sin intervención judicial, se afirma, no hay prueba, sino meros actos de investigación, que en ningún momento pueden fundamentar, por sí solos, una sentencia condenatoria. De contrario se vulneraría la presunción de inocencia. Estamos, creo, ante una posición doctrinal acertada.

2.-Interesa hacer alguna precisión sobre el derecho de información y el necesario y legalmente exigible secreto que se proyecta sobre las actuaciones de la Policía Judicial. 
Con independencia del efecto preventivo-general que quiera atribuirse a la información pública relativa a las actuaciones policiales en relación con el genérico derecho a la información, es lo cierto que las posibles informaciones de la actuación en casos concretos de la Policía Judicial habrá de someterse siempre a la consideración del Juez o Fiscal a cuyas órdenes se actúe, y en todo caso habrán de tenerse en cuenta las responsabilidades que se deriven, penales o disciplinarias, como consecuencia de revelaciones que afecten a la investigación y por su infundada influencia en el derecho constitucional a la intimidad y al honor, protegidos por el artículo 18 de la Constitución. Responsabilidades que derivarán de lo previsto en el art. 301 de la Lecrim y más aún si el procedimiento está declarado secreto incluso para las partes, habida cuenta lo prescrito en el art. 302 de la Lecrim. Responsabilidades penales en concepto de descubrimiento y revelación de secretos y responsabilidades disciplinarias, derivadas de la obligación de reserva, conforme al art. 15 del DPJ.

Debe significarse que las responsabilidades que derivan de tales preceptos de la Ley rituaria criminal afectan a la Policía Judicial y también al Ministerio Fiscal, y por supuesto al órgano judicial, siendo disponible tan sólo en ese marco una información general, de carácter sólo procedimental, que no afecte a la investigación en curso ni a los derechos fundamentales del art. 18 de la Constitución y que no conviertan en una paradoja injustificable el secreto en su caso acordado para las partes, ni la real indefensión que para estas supone la adopción del secreto.

3.-Por lo que se refiere a la doble dependencia funcional de la Policía Judicial, al Juez y al Fiscal, debe decirse que las Unidades adscritas están indistintamente afectas a ambos órganos. Así se concluye expresamente de lo regulado en la LOPJ, LOFCSE y DPJ.

El art. 789, en su texto conforme a la Ley $7 / 88$, establece que la Policía remitirá el original del atestado al Juez y copia al Ministerio Fiscal.

Por su parte, el art. 284 de la Lecrim establece que la Policía Judicial participará la instrucción de diligencias a la Autoridad Judicial o al representante del Ministerio Fiscal. Alternativa que parece concretar 
el art. 20 del DPJ. en los siguientes términos: "Cuando los funcionarios integrantes de las Unidades Orgánicas de la Policía Judicial realicen diligencias de investigación criminal formalmente concretadas a un supuesto presuntamente delictivo, pero con carácter a la apertura de la correspondiente actuación judicial, actuarán bajo la dependencia del Ministerio Fiscal. A tal efecto, darán cuenta de sus investigaciones a la Fiscalía correspondiente que, en cualquier momento, podrá hacerse cargo de la dirección de aquéllas, en cuyo caso los miembros de la Policía Judicial actuarán bajo su dependencia directa y practicarán sin demora las diligencias que el Fiscal les encomiende para la averiguación del delito y el descubrimiento y aseguramiento del delincuente».

Sin duda que este precepto del DPJ de 1987, parte de las funciones que ya el art. 5 del Estatuto del Ministerio Fiscal atribuía a éste, y parece ir en la línea de reforzar las competencias del Fiscal en una auténtica actividad instructora. Estos intentos, que no han llegado a término en la reforma de la Lecrim. de 1988, son claramente y con fortuna criticado por Segovia: «Parece que este Decreto intenta separar entre la instrucción material a cargo del Ministerio Fiscal y la formal atribuida al Juez; y aparte de que un Decreto no puede alterar el sistema vigente, es un intento de suprimir la instrucción a cargo del Juez y encomendarlo al Ministerio Fiscal». Frente a las ventajas que pueda comportar la unidad de criterio, suscita dicho autor las desventajas del pretendido sistema desde la perspectiva del principio de legalidad, reafirmando la necesidad de mantener la instrucción bajo el manto de la independencia judicial, al margen del principio de oportunidad y de cualquier intromisión de cariz político, la que afirma «es evidente que puede producirse por el carácter político que puede tener la actuación del Ministerio Fiscal».

Ciertamente que el citado precepto se sitúa, como se ha dicho, en un momento en que pretende formular de nuevo el modelo de procedimiento en la Lecrim, con la polémica surgida sobre la atribución o no de la instrucción al Ministerio Fiscal.

Debate que se ha reproducido con la ya mencionada Ley $7 / 88$, de 28 de diciembre, que plantea un conflicto aparente entre el art. 785 bis y el art. 789, ambos de la Lecrim, pues si bien el primero regula las dili- 
gencias de investigación del Fiscal, actuando a sus órdenes la Policía Judicial, el segundo de ellos comienza aludiendo a la obligación de la Policía Judicial de entrega de los atestados al Juez, con remisión de copia al Ministerio Fiscal.

Considero que realmente el art. 785 bis de la Lecrim no atribuye al Fiscal competencias que no tuviera ya por el art. 5 de su Estatuto.

Si es la Policía la que inicia un atestado, habrá de dar cuenta del mismo al Juez y copia al Fiscal. Al recibir el Juez dicho atestado se habrán ya incoado, si procede, las pertinentes diligencias; luego el Fiscal no podrá dirigir la investigación por sí mismo, siquiera sea porque lo establece el art. 785 bis. 3, dado que ya existe un procedimiento judicial sobre los hechos.

Dicho precepto de la Ley procesal penal permite, en suma, que el Fiscal dirija investigaciones si es por propia iniciativa, y no a instancias de un atestado ya incoado por la policía y en tanto no exista un procedimiento judicial. En tal caso, puede persistir en su investigación en tanto no haya persona concreta a la que imputar un delito, ya que en el momento de la investigación en que surja esta circunstancia, habrá de cesar en su investigación y remitir al órgano judicial competente lo actuado, por respeto al principio de tutela judicial efectiva y al derecho de defensa (art. 24 de la Constitución), posibilitando se haga efectivo y se cumpla lo dispuesto en el art. 118 de la Lecrim., eludiendo prácticas que generan indefensión de seguirse otro criterio. En tales diligencias de investigación fiscal la persona a la que se tiene por imputada no puede ejercer tales derechos con plenitud; y piénsese que a partir de que se tienen datos ciertos de su posible condición de imputada debe comunicársele, pues de contrario se vulneran los preceptos constitucionales precitados, y más aún si interviene en las diligencias del Fiscal como si fuera testigo, cuando realmente no lo es.

\section{Conclusiones}

Mi intervención en esta sesión debe finalizar, estableciendo las siguientes conclusiones generales: 
1.-La nueva regulación de la Policía Judicial, pese al modelo deliberadamente ambiguo adoptado, supone un avance desde la perspectiva de la independencia del Poder Judicial y de la eficacia material y jurídica de la investigación.

2.-Es necesario que se profundice en la formación especializada de los miembros de las Unidades Adscritas y que se potencie la sensibilidad judicial y policial sobre la exigible colaboración en orden a que en la práctica la Policía Judicial pueda efectivamente cumplir las funciones encomendadas. Sensibilización judicial en orden a que se utilicen realmente los instrumentos de investigación que la Ley ha puesto en sus manos. Sensibilización policial en orden a la exclusiva puesta a disposición, a los efectos de la investigación criminal, del Juez y, en su caso, del Ministerio Fiscal.

3. - La función atribuida al Ministerio Fiscal por la reciente normativa estudiada, nada nuevo añade respecto a la situación anterior y en concreto la derivada del Estatuto del Ministerio Fiscal. La mera investigación ni le estaba, ni le está vedada. Más aún, es conveniente por razones de dirección técnica y jurídica de la investigación. Sin embargo, no le está encomendada la instrucción. En el actual sistema procesal penal no son admisibles actuaciones que invadan la esfera judicial.

4.-Necesidad de desarrollar determinados contenidos del DPJ, en orden al mejor funcionamiento de la Policía Judicial, sobre:

a.-Naturaleza y funciones del Comisionado.

b.-Incidencia de la dependencia orgánica en la funcional, p. ej. en materia de ceses.

c.-Relación orgánica entre miembros de Unidades adscritas con mandos de Cuerpos de Seguridad, por razones de exigencia de la investigación criminal, sin que ello interfiera en la dependencia funcional.

5.-Necesidad de atribuir los medios materiales y humanos necesarios que hagan viable y efectivo el establecimiento real de las Unidades adscritas en las correspondientes Audiencias. De lo contrario, una vez más nos encontraremos con una prometedora reforma, con los defec- 
tos que se quiera en el orden conceptual y jurídico-práctico, pero con la peor de la limitaciones: la insuficiencia, sino carencia, para cumplimentar efectiva y eficazmente sus funciones. Quierase o no el hecho de situar materialmente a las Unidades adscritas en las sedes de las Audiencias o Juzgados es significativo para la configuración de la Policía Judicial como elemento de profundización de la independencia judicial. 